\title{
Inserção social - preconceito e deficiente auditivo
}

\author{
Social insertion - prejudice and hearing impaired \\ Inserción social - prejuicio y discapacidad auditiva
}

Recebido: 21/10/2021 | Revisado: 29/10/2021 | Aceito: 03/11/2021 | Publicado: 07/11/2021

\author{
Ivanete Vasconcelos de Souza \\ ORCID: https://orcid.org/0000-0002-2308-8952 \\ Centro Universitário Fametro, Brasil \\ E-mail. Ivanetevas.2019@gmail.com \\ Marcos Gabriel de Oliveira Xavier \\ ORCID: https://orcid.org/0000-0003-2992-4939 \\ Centro Universitário Fametro, Brasil \\ E-mail: Marcosgoxavier@hotmail.com
}

\begin{abstract}
Resumo
$\mathrm{O}$ artigo tem como foco evidenciar a inclusão das pessoas com deficiência auditiva no mercado de trabalho uma perspectiva da psicologia social no amparo dessas pessoas com deficiência auditiva (PCDA). Assim a psicologia social visa encontrar soluções para inserir as pessoas com deficiência no mercado de trabalho onde elas possam gozar de uma boa qualidade de vida. Sem maiores impactos psicossociais ao ingressarem no marcado de trabalho, mesmo sabendo que as políticas públicas são parcialmente eficazes. O objetivo geral visou discutir sobre os desafios das pessoas com deficiência auditiva no mercado de trabalho. A metodologia da pesquisa foi de natureza bibliográfica, descritiva e qualitativa. Por fim, mostrar que as políticas públicas não garantem o acesso ao mercado de trabalho para as (PCDA), por ser parcialmente ineficaz, ou seja, ineficiente em garantir a inclusão social da (PCD) no mercado de trabalho, pelo fato de não haver uma cobrança devida do setor público e privado, é tão difícil incluir socialmente a (PCDA) no mercado de trabalho, porque ainda existem muitos preconceitos e discriminações, muito embora, as pessoas com deficiência tenham os mesmos direitos, ainda falta muito empenho do poder público e também da sociedade no combate ao preconceito e a discriminação em relação a inserção das pessoas com deficiência, e precisam ser respeitadas na sua integralidade, como afirma o estatuto da pessoa com deficiência por meio da Lei 13.146/2015, que estabelece assegura e promove, a todas as pessoas com deficiência, condições iguais, exercício dos direitos e das liberdades fundamentais.
\end{abstract}

Palavras-chave: Mercado de trabalho; Deficiência auditiva; Psicologia Social.

\begin{abstract}
The article focuses on highlighting the inclusion of people with hearing impairment in the labor market from a perspective of social psychology in the support of these people with hearing impairment (PCDA). Thus, social psychology aims to find solutions to insert people with disabilities into the labor market where they can enjoy a good quality of life. No major psychosocial impacts when entering the labor market, even knowing that public policies are partially effective. The general objective was to discuss the challenges of people with hearing impairment in the labor market. The research methodology was bibliographical, descriptive and qualitative. Finally, to show that public policies do not guarantee access to the labor market for the (PCDA), as it is partially ineffective, that is, inefficient in ensuring the social inclusion of the (PCD) in the labor market, as there is no a due demand from the public and private sector, it is so difficult to socially include the (PCDA) in the labor market, because there are still many prejudices and discriminations, although people with disabilities have the same rights, there is still a lack of commitment from the public authorities and also of society in the fight against prejudice and discrimination in relation to the inclusion of people with disabilities, and they need to be respected in their entirety, as stated in the statute of people with disabilities through Law 13,146/2015, which provides for and promotes, to all people with disabilities, equal conditions, exercise of fundamental rights and freedoms.
\end{abstract}

Keywords: Labor market; Hearing deficiency; Social Psychology.

\section{Resumen}

El artículo se centra en destacar la inclusión de personas con discapacidad auditiva en el mercado laboral desde una perspectiva de psicología social en el apoyo a estas personas con discapacidad auditiva (PCDA). Así, la psicología social tiene como objetivo encontrar soluciones para insertar a las personas con discapacidad en el mercado laboral donde puedan disfrutar de una buena calidad de vida. Sin mayores impactos psicosociales al ingresar al mercado laboral, aun sabiendo que las políticas públicas son parcialmente efectivas. El objetivo general fue discutir los desafíos de las personas con discapacidad auditiva en el mercado laboral. La metodología de investigación fue bibliográfica, descriptiva y cualitativa. Finalmente, mostrar que las políticas públicas no garantizan el acceso al mercado laboral del (PCDA), ya 
que es parcialmente ineficaz, es decir, ineficiente para asegurar la inclusión social del (PCD) en el mercado laboral, ya que no existe una debida demanda del sector público y privado, es tan difícil la inclusión social del (PCDA) en el mercado laboral, porque aún existen muchos prejuicios y discriminaciones, aunque las personas con discapacidad tienen los mismos derechos, aún falta compromiso de los poderes públicos y también de la sociedad en la lucha contra los prejuicios y la discriminación en relación con la inclusión de las personas con discapacidad, y deben ser respetados en su totalidad, tal y como establece el estatuto de las personas con discapacidad a través de la Ley 13.146 / 2015 , que prevé y promueve, para todas las personas con discapacidad, la igualdad de condiciones, el ejercicio de los derechos y libertades fundamentales.

Palabras clave: Mercado laboral; Pérdida de audición; Psicología Social.

\section{Introdução}

A pessoa com deficiência auditiva (PCDA), por meio de conquistas legais, obtiveram sua inserção no mercado de trabalho, no entanto isso não garante de fato uma inserção social, pois eles dependem do emprego da língua de sinais e do reconhecimento dos reais desafios, necessidades e potencialidades dessas pessoas. Portanto, a inclusão no mercado de trabalho, com vista na psicologia social visa contribuir para inclusão e convívio com essa adversidade. O interesse pela temática surgiu a partir de discussões de estudantes acadêmicos de psicologia. Partindo disso esse trabalho tem como alvo as informações para conhecimento científico e para a elaboração de um artigo.

O Problema da pesquisa está na aceitação da sociedade na inclusão das pessoas com deficiência no mercado de trabalho, é influenciada pela perspectiva de como esta é compreendida. Essa compreensão é um dos fatores que interfere no psicológico estabelecidos para este grupo social.

A inclusão da pessoa com deficiência auditiva (PCDA), no mercado de trabalho requer apoio psicológico, diante das diferenças sociais das políticas públicas voltadas a esse público são eficazes à inclusão ao mercado de trabalho?

O Objetivo geral visou discutir sobre os desafios das pessoas com deficiência auditiva no mercado de trabalho.

Os objetivos específicos são: 1) Apresentar um perfil das pessoas com deficiência auditiva para conseguirem um emprego; 2) Os desafios do deficiente no mercado de trabalho; 3) Pré conceito e discriminação; 4) A participação do Psicólogo na organização.

Os olhares sobre a pessoa com deficiência auditiva sempre estiveram vinculados às concepções relativas à produtividade, a razão e a um padrão estético presente em cada contexto sociocultural. Ao longo do tempo, as pessoas com algum tipo de deficiências foram denominadas de diferentes formas: aleijada, retardada, excepcional e/ou deficiente - físico, mental, auditivo, visual- portadora de deficiência.

Atualmente, entende-se que a pessoa que possui qualquer tipo de disfunção e/ou deficiência, será chamada de Pessoa com Deficiência (PCD), tornando a terminologia mais adequada e sem estigma ou preconceito. Abordamos as dificuldades da inclusão do deficiente no mercado de trabalho. E ficou compreendido o trabalho como direito, constitui-se como tema desafiador quando se aborda a inclusão de pessoas com deficiência na sociedade e de modo particular no mundo do trabalho.

Segundo o Instituto Nacional do Seguro Social INSS (2019), as pessoas com deficiências (PCD’s) que não tem condições de trabalhar podem requerer aos benefícios. Por direito, baseada na Lei n $3298 / 99$, a pessoa com deficiência receberá do governo um salário-mínimo do Benefício de Prestação Continuada (BPC), independente de sua idade, para seu sustento, sua independência, já que não está apta para o trabalho, conforme defendido na Convenção sobre os Direitos das Pessoas com Deficiência.

\section{Referencial Teórico}

\subsection{Contextualizando a pessoa com deficiência na sociedade contemporânea}

No decorrer da história, várias atitudes frente às pessoas com deficiência foram vivenciadas. Segundo Donadel (2015, p. 12), na antiguidade, onde atividades como artesanato, agricultura e pecuária sobressaiam e os senhores eram os donos das terras, 
os indivíduos que nasciam com alguma "anormalidade" eram abandonados até a morte, assim como, as leis de Esparta e da Roma Antiga, que autorizava os patriarcas a matar seus filhos defeituosos.

Os hebreus acreditavam que a deficiência era uma forma de punição de Deus, e eram excluídos de participar de eventos religiosos. Já na Europa Medieval, por alguns eram considerados criaturas malignas, e por outros, criaturas divinas. Como, por exemplo, os hindus, que estimulavam a participação dos deficientes na igreja por considerarem a pessoa com deficiência visual com uma essência interior mais sensível. O cristianismo, portanto, defendia a pessoa com deficiência um ser racional, dotado de alma. A partir de então, deixando de ser aceitável a exterminação do indivíduo (Andrade, 2015, p. 65).

Para Ragazzi (2018, p. 22), "no início da história as pessoas com deficiência eram consideradas como "inválidas", consequentemente indivíduos sem valor, ou seja, inútil para a família e sociedade sendo este termo utilizado até o século XXI". Sendo assim até hoje no Brasil, milhares de pessoas com algum tipo de deficiência estão sendo discriminadas nas com unidades em que vivem ou sendo excluídas do mercado de trabalho. "O processo de exclusão social de pessoas com deficiência ou alguma necessidade especial é tão antigo quanto a socialização do homem" (Almeida, 2015, p. 33)

A falta de conhecimento da sociedade, em geral, faz com que a deficiência seja considerada uma doença crônica, um peso ou um problema. O estigma da deficiência é grave, transformando as pessoas cegas, surdas e com deficiências mentais ou físicas em seres incapazes, indefesos, sem direitos, sempre deixado para o segundo lugar na ordem das coisas. É necessário muito esforço para superar este estigma. Atualmente existem milhares de pessoas com deficiências especiais que são discriminadas nas escolas e no mercado de trabalho entre outros (Carvalho, 2015, p. 6).

\subsection{Inclusão social e movimentos sociais}

É comum vermos em revistas e TV, o tema inclusão na sociedade atual, seja ela qual for. Pessoas com necessidades especiais estão longe de serem integradas no mercado de trabalho ou em escolas, mas, ao mesmo tempo em que estão longe, lutam pelos seus direitos na sociedade.

Atualmente existem milhares de pessoas com deficiências especiais que são discriminadas nas escolas e no mercado de trabalho. Porém, durante o período medieval, mas especificamente em Esparta, na Grécia Antiga, pessoas portadoras de deficiências eram rejeitadas pela sociedade e pela família, eram lançadas ao mar ou até mesmo sacrificadas, pois existiam leis que permitiam esse ato. A cada ano a necessidade de inclusão das pessoas com deficiência na sociedade torna-se mais aparente (Brasil \& Goulart, 2015, p. 18).

Como consequência de diversas manifestações sociais em prol da causa, os governos começaram se dedicar a fazer políticas sociais que viabilizem a inclusão social dessa parcela da população. A partir de então houve a criação de diversos conselhos e programas como, por exemplo, o CONADE (Conselho Nacional dos Direitos da Pessoa Portadora de Deficiência) e a Política Nacional para a Integração da Pessoa Portadora de Deficiência, todas dedicadas a direcionar as ações governamentais (Conade, 2015, p.1).

Marinho (2016, p. 25), defende que "a inclusão social é um movimento mundial que se intensificou no Brasil e no mundo a partir da década de 90, tendo a ver com a mudança de entendimento do ponto de vista social, legal, ético, educacional, cultural e dos direitos humanos sobre a diferença e a deficiência".

"Paralelamente às ações do governo, a sociedade civil representada por ONGs, associações e cooperativas oferece sua contribuição para o combate à exclusão desse segmento da sociedade ao fundar Centros de capacitação, reabilitação, assistência social e de saúde" (Miranda, 2017, p. 42).

É importante ressaltar que para fins desta pesquisa, entende-se por pessoas com deficiência todos aqueles que apresentam um tipo ou mais de limitações funcionais, caracterizadas como permanentes ou temporárias, de causa congênita ou adquirida, podendo estar subdivididas em auditiva, visual, física, mental ou múltipla (Santos, 2015, p. 13). 


\subsection{Lei brasileira da inclusão}

A Lei 13.146/2015, conhecida como Lei de Inclusão, foi aprovada em 6 de julho de 2015, trazendo garantias fundamentais para a equiparação das pessoas com deficiência em relação à sociedade (Brasil, 2015, p. 23).

Deficiência de natureza física é caracterizam-se por alteração total ou parcial no corpo, sujeitando a pessoa ao comprometimento de funções motoras. Paralisias, amputações ou ausência de membros, nanismo, deformidades congênitas, paraplegias e tetraplegias são exemplos de deficiências físicas. Deficiências mentais ou intelectuais se caracterizam pela limitação do desenvolvimento mental da pessoa, ocasionando redução na capacidade cognitiva em comparação com a média da população geral ou da faixa etária (Monteiro, 2019, p. 56).

A deficiência mental pode ser congênita, sendo o exemplo mais conhecido a Síndrome de Down, ou ocasionada por múltiplos fatores, como traumatismo, doenças infecciosas e subnutrição no desenvolvimento infantil, entre outras. Deficiências sensoriais afetam um dos cinco sentidos, causando seu não funcionamento parcial ou total e incapacitando sua utilização plena (Patah, 2015, p. 38).

Embora, classicamente, as deficiências sensoriais sejam a surdez e a cegueira, outras formas de diminuição do tato, olfato e paladar podem ser enquadradas nessa classificação (Paim, 2018, p. 65).

Apesar da Lei de Inclusão já estar em vigência, ainda é necessário fazer com que todos os direitos vindos com ela produzam efeitos reais. Na teoria, o avanço é muito grande, mas é preciso que sua prática tenha condições de produzir efeitos satisfatórios, garantindo, realmente, que todos os direitos sejam efetivados (Brasil, 2015).

A Lei de Inclusão é um importante passo para garantir legitimidade à luta, mas sua implementação e obediência dependem ainda da conscientização das autoridades e da população em geral sobre a necessidade do respeito (Conade, 2015).

\section{Metodologia do Estudo}

A metodologia da pesquisa será a bibliográfica, descritiva com base na abordagem qualitativa, usando a análise dos dados usando a utilização de sites e banco de dados via internet para obter artigos que embase o estudo.

\subsection{Métodos}

Como elemento norteador desse artigo, o método utilizado nesta pesquisa foi o bibliográfico, descritivo e qualitativo pois, buscou-se em pesquisas realizadas nas literaturas, complementadas como estudos literários no sentido de explicitar o processo transformação das políticas públicas em relação aos defifientes auditivos e a inserção social para a inclusão no mercado de trabalho.

Para Sposito (2014, p. 35), "a questão do método é fundamental, porque se trata da construção de um sistema intelectual que permita, analiticamente, abordar uma realidade, a partir de um ponto de vista". Pois a metodologia como ciência não trata apenas das mudanças das formas dos estudos existentes, há muitos fatores que influenciam para o processo de modificação de cada projeto, sejam eles de exatas ou humanas, que neste caso específico trata das mudanças ocorridas ao longo das mudanças nas políticas públicas voltadas aos deficientes auditivos, influenciando os fatores que afetam a dinâmica em suas instâncias políticas, econômicas e sociais trabalhistas.

Com base no método utilizado procurou-se também a análise crítica da inclusão social do deficiente auditivo no mercado de trabalho, baseada em pesquisas de literaturas produzidas por teóricos os quais corroboram para a análise do objeto de estudo, como afirma Marconi e Lakatos (2012, p. 32), “esse é o princípio da identidade, que é o princípio da coerência, do acordo rigoroso do pensamento consigo mesmo", nesse sentido alinha-se a teoria com o conhecimento empírico de objeto de estudo. 


\subsubsection{Universo e amostra da pesquisa}

O universo da pesquisa será bibliográfico, a amostra será por meio dos dados obtidos através de leituras de (livros, revistas, jornais, sites, CDs entre outros), sendo a mais utilizada para todos os tipos de pesquisa.

\subsubsection{Seleção de sujeito da pesquisa}

A seleção do sujeito da pesquisa foi baseada nos critérios de classificação propostos por Vergara (2011), que a distingue sob dois aspectos: quanto aos fins e quanto aos meios.

Quanto aos fins, a pesquisa será caracterizada em bibliográfica por ser um sondagem, que segundo Yin (2012, p. 23):

A pesquisa bibliográfica é uma investigação ou sondagem por meio todo tipo de estudo e pode ser tratado como importantes estratégias metodológicas para a pesquisa onde ocorre um fenômeno ou dispõe de elementos para explicá-lo, pode incluir observações de documentos em base de dados entre outros. Portanto permite ao investigador um aprofundamento em relação ao fenômeno estudado, revelando nuances difíceis de serem enxergadas a olho nu.

Além disso, o estudo bibliográfico favorece uma visão holística sobre os acontecimentos da vida real, destacando-se seu caráter de investigação empírica de fenômenos contemporâneos. Vergara (2011, p. 43), define pesquisa bibliográfica como:

Um processo de resolver problemas concretos de soluções mais imediatas, ou não, com finalidades práticas que pretendem atingir e aplicar as teorias por meio das necessidades humanas e tecnológicas, suas principais características são: aplicação dos conhecimentos básicos; pode ou não ser reservada; produz produtos, processos e patentes; gera novas tecnologias e conhecimentos resultantes do processo de pesquisa.

Quanto aos meios, a pesquisa foi descritiva e qualitativa, segundo fonte de informações que foram coletadas em levantamento bibliográfico e por meio de todo tipo de publicações. Furasté (2015, P. 42) defende que:

O trabalho descritivo é um método de abordagem que descreve características de população ou fenômenos, tais como: fontes secundárias que abrangem bibliografias relacionadas ao tema de estudo, que vai desde revistas, publicações avulsas, internet, acervos e livros. Desta a pesquisa forma a pesquisa qualitativa tem como objetivo explicar e colocar o pesquisador em contato direto com tudo que foi escrito, dito, ou filmado sobre o respectivo assunto.

"Assim, este tipo de pesquisa é sem dúvida uma reprodução sobre o que prontamente significou o tema em estudo, mas também propicia sobre o assunto um novo enfoque chegando a acabamentos inovadores, conforme as autoras" (Lakatos \& Marconi, 2010, p. 18).

\subsubsection{Instrumento de coleta de dados}

O instrumento de coleta de dados será de natureza descritiva e qualitativa. Segundo Gil (2010, p. 22), a principal finalidade das pesquisas descritivas e qualitativas é desenvolver, esclarecer e modificar conceitos e ideias, tendo em vista, quanto a formulação de problemas mais preciosos ou hipótese pesquisáveis para estudos posteriores". Nessa perspequitiva, a Figura 1, apresenta o fluxograma dos procedimentos metodológicos. 
Figura 1 - Fluxograma dos Procedimentos Metodológicos.

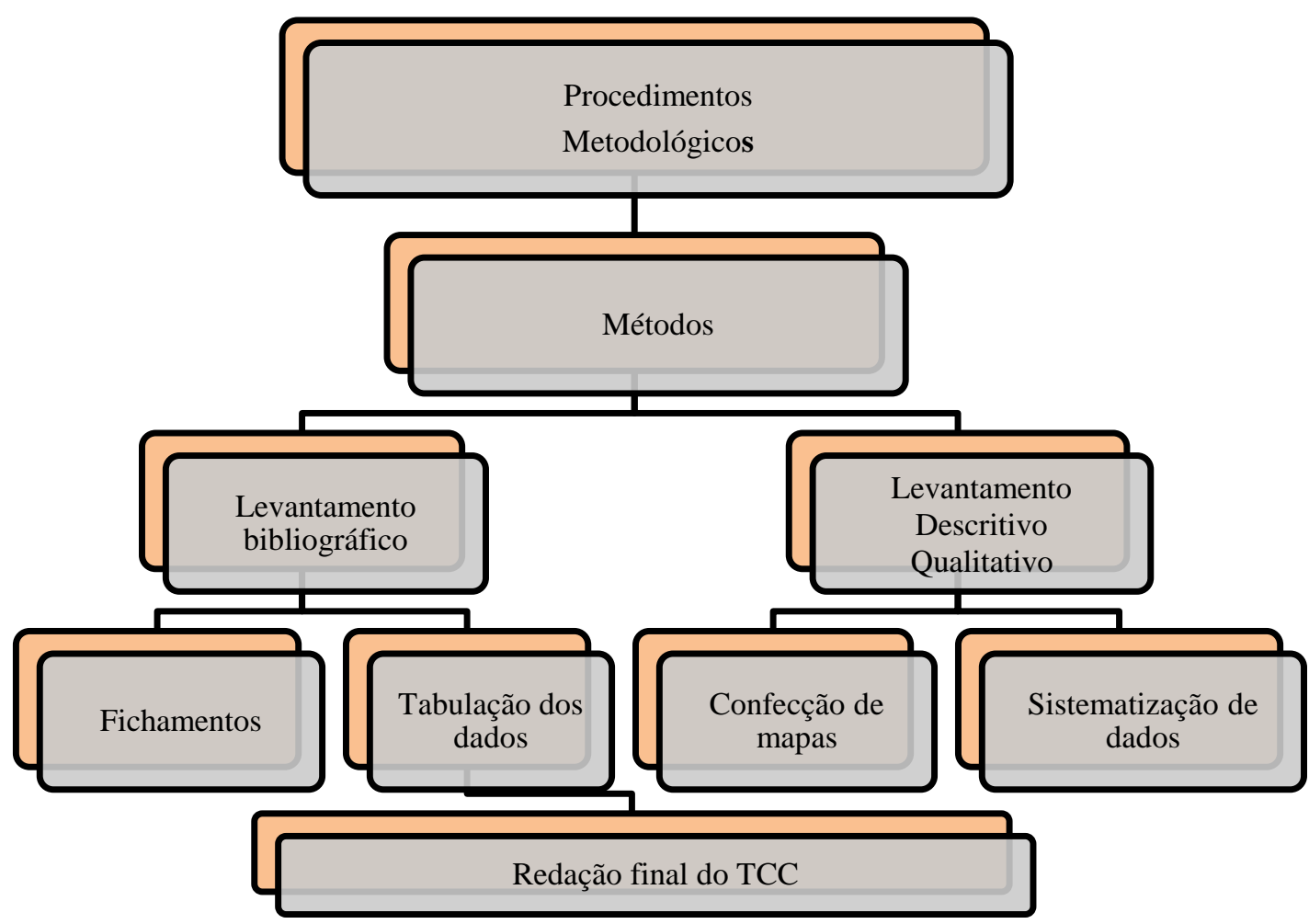

Fonte: Equipe (2021).

A busca de dados objetivou um desenvolvimento adequado e sempre dentro dos limites do método qualitativo, é importante salientar que, conforme Lakatos (2010, p. 33), argumenta "a metodologia é o conjunto de métodos ou caminhos que são percorridos na busca do conhecimento, essa busca resultará em uma análise crítica dos dados coletados aliados ao embasamento científico das literaturas pesquisadas".

\section{Resultado}

A pesquisa bibliográfica que subsidiou a presente revisão teórica que foi baseada na consulta de trabalhos publicados nos últimos 5 anos (2015 a 2020). Tal pesquisa, que visou buscar em bancos de dados às análises da produção científica da literatura nacional, conforme as palavras chaves e base de dados, apresentados a seguir conforme Tabela 1 .

Tabela 1 - Palavras-chaves e número de trabalhos encontrados das respectivas bases de dados.

\begin{tabular}{l|c|c|c}
\hline \multicolumn{1}{c|}{ Palavras-chave } & Google Acadêmico & Periódicos Capes & $\begin{array}{c}\text { SCIELO, SCOPUS, } \\
\text { LILACS, PUBMED, } \\
\text { CINAHL, BDENF }\end{array}$ \\
\hline Mercado de Trabalho & 2 & 4 & 3 \\
\hline Deficiência Auditiva & 2 & 2 & 3 \\
\hline Psicologia Social & 1 & 1 & 3 \\
\hline Total & \multicolumn{2}{|}{} \\
\hline
\end{tabular}

Fonte: Equipe (2021).

Para seleção de trabalhos foram utilizados os seguintes critérios de inclusão: 1) artigos publicados nos três principais periódicos da área de Psicologia social: 2) Idiomas: inglês e português 3) Tópicos escolhidos Amparo a pessoa com deficiência auditiva, inserção social para os (PDCA). Os critérios de exclusão foram os artigos publicados anteriormente ao ano de 2015, que 
se apresentavam duplicados e repetidos, como também artigos em inglês e espanhol, editoriais, relatos de experiência, estudos de caso e que não atendiam a finalidade da temática.

Na primeira etapa foram encontrados 862 artigos, que foram submetidos a primeira etapa sobre o deficiente de um modo amplo. Após a leitura minuciosa dos títulos dos artigos selecionados de acordo com a temática abordada na pesquisa, foram selecionados de 74 artigos. Posteriormente à leitura dos resumos, apenas 32 estudos foram selecionados para serem incluídos na leitura crítica e integral. Por fim, restaram 18 estudos que atenderam aos critérios de inclusão sobre as psicologia social no amparo a pessoa com deficiência auditiva, e a inserção no mercado de trabalho. Verificou-se que, o maior número de artigos foi encontrado na base de dados dos periódicos Capes seguido do Google Acadêmico, e a minoria ficou para LILACS, PULBMED, SCORPUS, CINAHL E BDENF, a SCIELO não foi positiva para resultados, a Tabela 2, mostra esses resultados.

Tabela 2 - Resultados das Buscas nas bases de dados.

\begin{tabular}{|c|c|c|c|c|c|c|c|}
\hline \multicolumn{8}{|c|}{ Buscas } \\
\hline \multicolumn{8}{|c|}{ Total de 862 Artigos encontrados } \\
\hline \multirow{2}{*}{\multicolumn{2}{|c|}{$1^{\mathrm{a}}$ Etapa }} & LILACS & PULBMED & SCORPUS & CINAHL & SCIELO & BDENF \\
\hline & & 48 & 364 & 238 & 102 & 51 & 59 \\
\hline \multicolumn{8}{|c|}{ Aplicação dos critérios de inclusão e exclusão } \\
\hline \multirow{2}{*}{\multicolumn{2}{|c|}{$\begin{array}{l}2^{\mathrm{a}} \text { Etapa } \\
74 \text { Artigos }\end{array}$}} & LILACS & PULBMED & SCORPUS & CINAHL & SCIELO & BDENF \\
\hline & & 7 & 29 & 12 & 11 & 8 & 7 \\
\hline \multicolumn{8}{|c|}{ A importância da inserção do deficiente no mercado de trabalho } \\
\hline \multirow{2}{*}{\multicolumn{2}{|c|}{$\begin{array}{l}3^{\text {a }} \text { Etapa } \\
32 \text { Artigos }\end{array}$}} & LILACS & PULBMED & SCORPUS & CINAHL & SCIELO & BDENF \\
\hline & & 6 & 15 & 4 & 2 & 3 & 2 \\
\hline \multicolumn{8}{|c|}{$4^{\text {a }}$ Etapa 17 Artigos } \\
\hline \multicolumn{8}{|c|}{$\begin{array}{l}\text { INCLUSÃO DAS PESSOAS COM DEFICIÊNCIA AUDITIVA NO MERCADO DE TRABALHO: Uma } \\
\text { Perspectiva da Psicologia Social. }\end{array}$} \\
\hline $\begin{array}{l}\text { Google } \\
\text { Acadêmico }\end{array}$ & $\begin{array}{l}\text { Periódicos } \\
\text { Capes }\end{array}$ & LILACS & PULBMED & SCORPUS & CINAHL & SCIELO & BDENF \\
\hline 5 & 7 & 2 & 1 & 2 & 1 & 2 & 1 \\
\hline \multicolumn{7}{|c|}{ Total } & 21 \\
\hline
\end{tabular}

Fonte: Equipe (2021).

Assim, obteve-se uma amostra de 74 estudos no final da segunda etapa de avaliação dos artigos, 7 (14,04\%), foram encontrados na LILACS, na PULBMED, 29 (24,65\%), na SCORPUS, 12 (16,05\%), na CINAHL, 11 (15,52\%), na SCIELO, 8 $(15,70 \%)$, e $7(14,04 \%)$ na BDENF.

$\mathrm{Na}$ terceira etapa procedeu-se a leitura completa dos 74 artigos a fim de identificar aqueles que não respondiam satisfatoriamente o tema em questão ou não tinham pertinência com o objetivo do estudo, desse processo obteve-se uma amostra de 32 artigos, sendo eles, 6 (29,68\%) da LILACS, na PULBMED, 15 (42,53\%), na SCORPUS, 4 (10,73\%), na CINAHL, 2 (5,84\%), na SCIELO, 3 $(5,38 \%)$, e $2(5,84 \%)$ na BDENF.

$\mathrm{Na}$ quarta etapa as análises dos resultados foram feitas em forma de fichamento organizando, todos os artigos por meio das avaliações e visualização dos dados, nesse processo foram identificados um número muito baixo de artigos que faziam parte do estudo, dessa forma, foram feitas buscas no Google Acadêmico e periódicos Capes onde foram encontrados um número maior de artigos que condiziam com a situação real do estudo e que embasaram satisfatoriamente o estudo sobre a questão da psicologia social no amparo a pessoa com deficiência auditiva e a inserção dela no mercado de trabalho, neste processo obteve-se uma amostra de 17 artigos, sendo eles, 5 (35,2 \%), Google Acadêmico, 7 (35,8\%), Periódicos Capes, 2 (4,83\%) da LILACS, na PULBMED, 1 (4,83\%), na SCORPUS, 2 (4,83\%), na CINAHL, 1 (4,83\%), na SCIELO, 2 (4,83\%), e 1 (4,83\%) na BDENF. 
Os resultados enfatizaram as qualidades dos 21 artigos incluídos nas categorias que foram evidenciadas a partir dos resultados dos estudos selecionados: As políticas públicas no amparo a pessoa com Deficiência Auditiva: os desafios das pessoas com deficiência auditiva no mercado de trabalho. $\mathrm{O}$ perfil das pessoas com deficiência auditiva para conseguirem um emprego; $\mathrm{O}$ desafios do deficiente no mercado de trabalho; Pré conceito e discriminação; A participação do Psicólogo na organização. Portanto, os dados identificaram alguns pensadores que buscaram descrever os ditos e conhecimentos dos atores sobre o assunto proposto. A revisão integrativa foi tratada e analisada na forma de sistematização do conhecimento, ela abrange a leitura, análise e interpretação de artigos em bibliotecas virtuais. É um trabalho sistemático para construção dos conhecimentos, colaborando, reproduzindo, detalhando, atualizando e ampliando o conhecimento. "O tipo de pesquisa que se classifica como "integrativa", tem por premissa buscar a resolução de problemas melhorando as práticas por meio da observação, análise e descrições objetivas, com exímios fatos para a padronização de técnicas e validação de conteúdo".

A inclusão da pessoa com deficiência (PCDA), no mercado de trabalho requer apoio das instituições públicas e privadas, diante das diferenças sociais as políticas públicas voltadas as (PCD), são eficazes na inclusão ao mercado de trabalho? A resposta aparentemente é negativa, porém o conceito de deficiência tem evoluído ao longo dos tempos, em decorrência das mudanças na sociedade, assim como as conquistas alcançadas pelas pessoas portadoras de deficiência auditiva. As diretrizes que norteiam a política para implementação nas três esferas de gestão e as parcerias interinstitucionais necessárias, conforme Tabela 3.

Tabela 3 - Resultado do tema proposto.

\begin{tabular}{c|c|c}
\hline $\mathbf{N}$ & Embasamento & Consequências \\
\hline 1 & Promoção da Qualidade de Vida & Deficiente Vive Mais \\
\hline 2 & Atenção ao Deficiência & Inclusão Social \\
\hline 3 & Atenção Integral a Saúde & Direitos Humanos \\
\hline
\end{tabular}

Fonte: Equipe (2021).

Portanto, fazendo uma análise dos artigos estudados é constitucional que toda e qualquer pessoa tem direitos e deveres, para tanto, A Política Nacional de Saúde da Pessoa com Deficiência Auditiva (Portaria $\mathrm{n}^{\circ}$ 10.060/2002), tem como propósito reabilitar a pessoa com deficiência na sua capacidade funcional e desempenho humano, colaborando para a sua inclusão total na vida social, e proteger a saúde mental deste grupo populacional, como também evitar agravos que ocasionem a exclusão social por meio de problemas psicológicos.

\section{Discussão}

\subsection{O perfil das pessoas com deficiência auditiva para conseguirem um emprego}

Um dos principais e mais recentes referenciais da inclusão das pessoas com deficiência é a inserção no mercado de trabalho formal Passos (2016, p. 15), esta inclusão começou efetivamente quando a Constituição Federal garantiu os direitos de acesso à educação, ao trabalho, às formas de interação social, como o esporte e o lazer, entre outros, às pessoas com deficiência. E, com a homologação da Lei no 8.213, Art. 93 (1993), o acesso ao trabalho ganhou considerações específicas. 
A lei determina que toda empresa com 100 ou mais empregados está obrigada a preencher de $2 \%$ a $5 \%$ dos seus cargos com beneficiários reabilitados ou pessoas portadoras de deficiência. Essa lei contribuiu para uma crescente preocupação com a empregabilidade formal de pessoas com deficiência e sua inserção no mercado de trabalho (Ribeiro, 2019, p. 29)

Como consequência, instituições sociais, como as de educação, foram incumbidas da missão de preparar tais pessoas para o mercado de trabalho, até então escasso, transformando a via de acesso ao trabalho para as pessoas com deficiência e transformando também o acesso à educação, de modo a possibilitar uma mudança na situação social dessas pessoas e viabilizar sua inclusão nos meios sociais (Vieira, 2016, p. 33).

\subsection{Os desafios do deficiente no mercado de trabalho}

Os estudos indicam as dificuldades o processo de inserção no mercado de trabalho, como falta de conhecimento dos direitos, as dificuldades ao acesso à educação formal e aos programas de qualificação profissional, o receio em buscar um emprego é abrir, mão de benefícios já adquiridos (Freitas, 2019, p. 42).

Nessa conjuntura, surgia então a necessidade da formação de cidadão produtivo, foi aí que surge uma maior responsabilidade pública pelas necessidades da (PCDA), pois eles começaram a ser vistos como potencialmente capazes de executar tarefas industriais (Sassaki, 2015, p. 13).

"Desse modo as pessoas com deficiência tinham um único direito, que era de estar inserido no mercado profissional, porém não para serem reconhecidos como cidadãos, mas sim para cumprir a necessidade do sistema capitalista" (Freitas, 2019, p. 45).

Portanto nessa época não existia uma acessibilidade adequada para as pessoas com deficiência, tampouco elas tinham a possibilidade de qualificação, visto que as empresas do sistema capitalista recorriam a essas pessoas somente pelo aumento da mão-de-obra, isso quer dizer que essas pessoas não tinham nenhuma importância para o sistema de fazer carreira (Monteiro, 2019, p. 10).

No mercado de trabalho, os portadores de deficiência auditiva são vistos como geradores de custos, ou seja, a sua inserção nas empresas depende não só da superação de preconceitos, mas também da viabilização econômica de sua adaptação - a acessibilidade, tão discutida hoje em dia. "Quebrar as barreiras arquitetônicas existentes nos estabelecimentos para, a partir de então, receber este grupo requer gastos extras, que muitas empresas não estão dispostas a pagar” (Carvalho, 2015, p. 22).

Somado a isto, existe o fato de que, algumas dessas pessoas com deficiência auditiva necessitam, às vezes (como qualquer outra pessoa sem deficiência) se afastar para realizarem algum tipo de tratamento ou consultas especializadas, o que, para as empresas, pode implicar em prejuízos em termos de produtividade (Passos, 2016, p. 51).

A própria sociedade cria problemas e barreiras para as pessoas com deficiência, causando-lhes incapacidades ou desvantagens no desempenho de papéis sociais. Essas barreiras consistem em: políticas discriminatórias e atitudes preconceituosas que rejeitam as minorias e as suas diferenças, desconhecimento das necessidades especiais e direitas das pessoas com deficiência, entre outros. 'E é no mercado de trabalho que essas barreiras se tornam ainda mais contundentes” (Romero, 2020, p. 31).

A PCDA está finalmente sendo vista pela psicologia social como um sujeito capaz profissionalmente de assumir atividades e responsabilidades através de sua correta capacitação, o que a coloca no mercado de trabalho. "Para que haja inclusão social, uma das principais atividades é proporcionar a PCDA a possibilidade de poder trabalhar, de mostrar a sociedade que é capaz de se desenvolver e se responsabilizar por uma atividade" (Carvalho, 2015, p. 43). 


\subsection{Pré conceito e discriminação}

"Combater o preconceito contra surdez não deve ser uma luta apenas dos deficientes auditivos; combater o preconceito contra o surdo mesmo sendo ouvinte não se constitui como um "favor", mas sim como um princípio de supressão da violência social" (Monteiro, 2019, p. 35).

Portanto, o (PCDA), pode ser alvo de discriminação, contudo, é dever moral de constituir uma sociedade humana e mais inclusiva e igualitária, para tal, é fundamental perceber que os Direitos Humanos não são meras políticas, se trata de uma questão humanitária de sobrevivência humana (Marinho, 2016, p. 52).

Preconceito é aquele olhar de pena. É a exclusão que o deficiente auditivo sofre quando os ouvintes próximos não fazem esforço algum para inclui-los nas conversas. Também é a generalização destorcida que faz os ouvintes até os dias de hoje acreditarem que todo surdo e mudo usa libras. Contudo, Goffman (2015, p. 18), sustenta que "a convivência não dirime totalmente a discriminação e o preconceito, sendo assim o preconceito das discriminações em previsões sociais continuam sendo constituídas por meio das categorias nas quais os deficientes auditivos são encaixados". Tais expectativas são sempre relembradas quando se entra em contato com alguém que vivencia o processo de preconceito e discriminação.

Goffman (2015, p. 19), define "o preconceito e a discriminação como um atributo considerado profundamente depreciativo pelo meio social, que conduz o indivíduo ao descrédito de forma intensa". O deficiente auditivo que sofre preconceito e discriminação é visto, como defeituoso, fraco ou em situação de desvantagem em relação aos demais ouvintes.

Portanto, ainda se vivencia a indiferença, o ignorar a existência, a subestimação tanto nas instituições de ensino, assim como no ambiente profissional. Por isso será muito pouco provável que o deficiente auditivo com qualificações, inclusive com graduação, seja visto em balcões de estabelecimentos comerciais ou trabalhando como autônomos, por não conseguirem transpor a barreira para a profissionalização. Contudo o panorama do preconceito e discriminação no ambiente de trabalho para os deficientes auditivos refletem a fraca inclusão no mercado capitalista.

\subsection{A participação do Psicólogo na organização}

O papel do psicólogo dentro das organizações é atuar como facilitador e conscientizador dos vários grupos que compõem a instituição, considerando a saúde e a subjetividade dos colaboradores, a dinâmica da empresa e a sua inserção no contexto mais amplo da organização. Lobato (2015, p. 22), conceitua que a psicologia organizacional é uma área que está inserida no campo relativo ao trabalho e tem estreito vínculo com as atividades administrativas. Porém suas metas extrapolam a visão tradicional de ajustamento das pessoas com deficiência auditiva no trabalho em busca da eficiência máxima.

Para tanto, o papel do psicólogo dentro de uma organização é de suma importância para os indivíduos com deficiência auditiva, pois, é esse profissional que valoriza a adequação do deficiente ao posto de trabalho, dando autonomia, credibilidade e segurança a todos os envolvidos como causa de participação, não deixando o deficiente nas mãos de quem não sabe lhe-dar com a questão.

Em algumas famílias e comunidades, as pessoas com deficiência, por razões diversas, ainda são discriminadas e excluídas socialmente. Os mitos e preconceitos sobre as deficiências ainda existem e dificultam os relacionamentos e inclusão de pessoas com deficiência. Portanto, Lobato (2015, p. 43), relaciona que é importante considerar as seguintes discursões conforme o Quadro 1. 
Quadro 1: Participação do Psicólogo em relação aos objetivos propostos.

\begin{tabular}{|l|}
\hline Participação do Psicólogo em relação aos objetivos propostos \\
\hline 1) É necessário, falar sobre a deficiência, suas causas, dificuldades, preconceitos, discriminação, \\
necessidades e possibilidades; \\
\hline 2) Se a pessoa for uma criança, oriente a família e ajude a encaminhá-la para a escola, para programas de \\
reabilitação, se for o caso, e para outras oportunidades de inclusão e participação. A criança deve brincar e \\
interagir com outras crianças e com outros adultos. Isso ajuda o seu desenvolvimento; \\
\hline 3) A escola contribui de forma decisiva para o desenvolvimento e inclusão de pessoas com deficiência, \\
aceitando a sua matrícula e fazendo as adaptações necessárias, como: rampas, portas, banheiros, corrimãos, \\
corredores e pisos derrapantes, materiais e conteúdos pedagógicos e a avaliação da aprendizagem; \\
\hline 4) Devemos dar às pessoas com deficiência todas as condiç̃̃es de acesso aos bens e serviços sociais, para \\
que elas participem de forma efetiva de experiências e atividades como excursões, esportes, teatro e música; \\
\hline 5) Se souber de uma pessoa com deficiência que vive sozinha, isolada, convide-a para passear pelas \\
redondezas, para estabelecer contatos e fazer novas amizades; se for o caso, ajude-a a encontrar um trabalho; \\
\hline 6) Possibilite a participação da pessoa com deficiência nas atividades comunitárias pelas quais tenha \\
preferência, informando-a sobre reuniões, festas e atividades religiosas; \\
\hline \multicolumn{2}{|c|}{ 7) A pessoa com deficiência pode assumir funções e responsabilidades em vários segmentos da sociedade, } \\
como conselhos, comissões religiosas e escolas, dentre outras.
\end{tabular}

Fonte: Adaptado de Lobato (2015).

Dentro da participação do psicólogo organizacional Zanelli (2015, p. 31), destaca que "o psicólogo é que orienta a definição das atividades que os deficientes podem exercer nas organizações, portanto", fica claro, a seleção de pessoal ou uso de instrumentos psicológicos para avaliar o ajuste do deficiente auditivo ao campo de atuação, sendo assim, se mostra em completa limitação a circunscrição tradicional da área.

\section{Considerações Finais}

$\mathrm{O}$ atendimento das pessoas com deficiência auditiva em instituições nos aspectos inclusivos, atingiram consistência no cenário brasileiro, quando se iniciou o debate mundial sobre a Trabalho para todos envolvendo diversos países e culminando com definição de diretrizes para a reorganização dos sistemas de mão-de-obra no Brasil.

Entre inúmeras diretrizes dessa reorganização trabalhista, tem-se uma vasta legislação para a acessibilidade e, em destaque, a garantia de que o deficiente terá acesso urbanístico, arquitetônico, mobiliários, equipamentos no interior das empresas regular comumente chamada de empresa inclusiva. Essa acessibilidade também se traduz em portas abertas de todas as empresas brasileiras para o trabalho, permanência e terminal idade de trabalho, ou seja, empresas equipadas e/ou adaptadas com rampas, banheiros, elevadores e demais itens instalados nessas empresas que possam dar comodidade para que o colaborador seja deficiente visual, cego, deficiente auditivo, aluno com déficit intelectual, trabalhador com déficit de mobilidade e todos os colaboradores que dessa empresa for trabalhar.

Em Manaus, umas grandes parcelas dessa população, em destaque trabalhadores com mobilidade reduzida e colaboradores cegos são os mais prejudicados, uma vez que um dos maiores empecilhos para essas pessoas são as barreiras arquitetônicas que se traduzem em empresas sem estrutura física adequada pensada para pessoas sem nenhuma deficiência, em 
vez das pessoas que utilizam cadeiras de rodas, bengalas, muletas, e há de destacar as placas em Libras ou em Braille, bem como os sinalizadores visuais.

Outro destaca que chama muito a atenção da sociedade e, em especial dos trabalhadores com deficiência que precisam trabalhar é a falta de acessibilidade de locomoção, ou seja, uma parcela significativa dessa população se locomove de um bairro a outro e precisa enfrentar calçadas sem nenhuma estrutura com buracos e impedimentos, com tantas dificuldades, a evasão trabalhista de muitos deficientes aumentam, uma vez que as inúmeras dificuldades influenciam não só o pessoal, mais o social ocorrendo assim a exclusão do ambiente de trabalho.

O conceito de acessibilidade deve ser respeitado em todas as áreas sociais, a eliminação de barreiras arquitetônicas deve ser um compromisso de todos, principalmente pautados nas políticas públicas que são os responsáveis pela melhoria da qualidade de inclusão e bem-estar da população com deficiência. Pessoas com deficiência Auditiva ou com alguma limitação devem ter a liberdade de ir e vir. É importante destacar ainda que o termo acessibilidade não se refere apenas em barreiras arquitetônicas, mas o acesso à informação, a comunicação, equipamentos e programas adequados a inclusão para todos os deficientes.

O profissional psicólogo deve ser capaz de se fazer compreender que esse abalo psicológico nos (PDCA), tem mais a ver com a gestão de participação das políticas públicas do que com a capacidade das pessoas com essa deficiência. Portanto isso causa um abalo psicológico nas pessoas com deficiência seja ela auditiva ou não. Num entanto aumenta significativamente o número de pacientes (PDCA) com problemas de se achar incapaz para o mercado de trabalho, sendo assim essa é uma questão de políticas públicas, onde fica registrado tratar dessa questão política em trabalhos futuros.

\section{Referências}

Andrade, E. N. A (2015). Atuação das políticas públicas na promoção, incentivo e apoio ao Deficiente Auditivo. Revista de psicologia contemporânea. Publicado em julho no banco de dados do CINAHL. https://www.atuaçãodopsicologo_naautoajuda.2019.

Almeida, J. M. (2015). Apoio ao Deficiente Auditivo pelos Profissionais de Saúde: Revisão Integrativa da Literatura. Capes. Rev. Paul. 33(3):355-362 Psicologia. Disponível em: 〈http://www.scielo.br/pdf/rpp/v33n3/0103-0582-rpp-33-03-0355.pdf>.

Brasil, M. A. (2015). A importância do Emprego para o deficiente Auditivo. Revista Saúde Brasil. Google Acadêmico. https://saudebrasil.saude.gov.br/eu-queroviver- melhor/a-importância-do-emprego.

Carvalho, F. L. (2015). Fatores Associados ao Emprego Exclusivo para Deficiente Auditivo no Brasil: Revisão Sistemática. Capes. Revista Saúde e Equilíbrio. Psicologia - RN. 2015. 〈https://www.scielosp.org/pdf/rsp/2015.v49/91/pt>

Donadel, Marilene de Fátima - CRB 9/924. (2015). A pessoa com deficiência na sociedade contemporânea: problematizando o debate / organizador: P475. Programa Institucional de Ações Relativas às Pessoas com Necessidades Especiais - PEE - (2 ${ }^{\text {a }}$ Ed). Cascavel: Edunioeste.

Fachin, Odília. (2010). Fundamentos de Metodologia. (3. Ed.) Saraiva.

Furasté, Pedro Augusto. (2015). Normas Técnicas para Trabalhos Científicos: Explicitação das Normas da ABNT - (17 ed.). Editora. Dáctilo Plus.

Fonseca, R. T. M. (2016). O trabalho da pessoa com deficiência e a lapidação dos direitos humanos: o direito do trabalho, uma ação afirmativa. São Paulo, SP: LTr.

Flick, Uwe. (2009). Introdução à pesquisa qualitativa. 2 Ed., Tradução Nertz. São Paulo: ARTMED.

Gil, A. (2010). Fundamentos de Metodologia Científica. (8 ${ }^{\text {a }}$ Ed.) Atlas.

Goulart, B. N. G. (2015). Aspectos Socioeconômicos e Conhecimento Sobre Políticas Públicas na inserção do deficiente ao Mercado de Trabalho. SCORPUS. Revista Audiol 20 (2):141-5. http://www.capes.br/pdf/acr/v20n2/2317-6431-acr-20-2-0141.pdf.

Goffman, E. (2015). Preconceito e Discriminação. A identidade deteriorada. (6 ${ }^{\mathrm{a}}$. Ed.). Zahar.

Lakatos, Eva Maria; Marconi, Mariana de Andrade. (2010). Fundamentos da Metodologia Cientifica. (5a ed.) São Paulo.

Lobato, D. M. (2015). Estratégia de Empresas com a Participação do Psicólogo. (4ª Ed.) FGV.

Marinho, A. Desmame: (2016). A importância do Emprego para a vida dos Deficientes. Revista Saúde. Google Acadêmico. https://www.empregoparavida.com.br/noz.

Miranda, L.; (2017). O Papel do Governo no Sucesso para o Emprego para os Deficientes: Revisão de Literatura. LILACS. Revista. RIASE. 3(1). abril. <http://dspace.uevora.pt/rdpc/bitstream/10174/22773/1/180-735-1-PB.pdf>

Monteiro, F. (2019). Entenda a importância do Amparo das Políticas Públicas Para a Vida dos deficientes auditivos. Revista Saúde. Google Acadêmico. Taquei. https://www.conquistesuavida.com.br/not. Acesso em: 06/03/2020. 
Research, Society and Development, v. 10, n. 14, e406101422115, 2021

(CC BY 4.0) | ISSN 2525-3409 | DOI: http://dx.doi.org/10.33448/rsd-v10i14.22115

Paim, J. S. (2018). Fatores Associados à Prática e a Duração do Emprego do Deficiente no Brasil Contemporâneo. Google Acadêmico. Revista Investigação, 17(3):66-74. <http://publicacoes.unifran.br/index.php/investigacao/art

Patah, D. (2015). A importância do Trabalho e o Desejo do Deficiente pelo Emprego Desejado: Impasse nas Políticas Públicas. Revista Correios da SBP. São Paulo, v. 11, n. 1, p.20-22. Capes. https://www.nescon.medicina.ufmgcapes.br/biblioteca/.

Passos, L. (2016). Profissionais de Saúde na Promoção ao Emprego do Deficiente Auditivo: Revisão Integrativa. Periódicos Capes. Revista Ver enfermagem UFPE online., Recife, 10(supl.3):1507-16, abr. Capes. <https://periodicos.ufpecapes.br/revis.

Santos, T. R. Alves, F. P. França, Júnior, W. R. da Silva. (2015). Políticas públicas direcionadas às pessoas com deficiência: Uma Reflexão Crítica. Revista Ágora.

Sassaki, Romeu Kasumi (2015). Inclusão: Construindo uma Sociedade para Todos. (7.ed.). WVA.

Ragazzi, Ivana Aparecida Grizzo. (2018). Ações afirmativas: a inclusão das pessoas portadoras de deficiência no mercado de trabalho. In: XVII CONGRESSO NACIONAL DO CONPEDI, realizado em Brasília-DF nos dias 20, 21 e 22 de novembro de 2018.

Ribeiro, M. A.; \& Carneiro, R. (2019). A inclusão indesejada: as empresas brasileiras face à Lei de Cotas para pessoas com deficiência no mercado de trabalho. Organizações \& Sociedade,16(50), 545-564. doi:10.1590/S1984-92302009000300008.

Romero, M. J. S. (2020). “História da Educação e Trabalho para Pessoa Especial no Brasil”, em Temas em Educação, São Carlos.

Vergara, S., C. (2011). Projetos e Relatórios de Pesquisa em Administração. (13ª . ed.) Atlas.

Vieira, T. O. (2016). Intenção de dar Emprego a Pessoa com Deficiência Auditiva: Revisão Sistemática. Scielo. Revista. Ciência \& Saúde Coletiva, 21(12):38445$3838<$ http://www.scielos.br/pdf>

Yin, R. K.; (2012). Estudo de caso: planejando métodos. (4ª ed.) Bookman.

Zanelli, J. C. (2015). Psicologia Organizacional e Trabalho no Brasil. (4ª Ed.) Artmed. 